\title{
La necesaria puesta al día del régimen de la modificación de la obligación en el Código civil español
}

\author{
Moisés Barrio Andrés \\ Abogado. Letrado del Consejo de Estado \\ Profesor de Derecho en ICADE (Madrid)
}

Recibido: 15.04 .2011

Aceptado: 10.10.2011

\begin{abstract}
Resumen: Este artículo pretende ofrecer una perspectiva jurídico civil de los aspectos más relevantes de la modificación de las obligaciones en el Código civil español. Se analiza en primer término las dificultades conceptuales existentes para examinar seguidamente los distintos supuestos, con especial consideración de los aspectos problemáticos. Finalmente, se sugieren diversas líneas de reforma.
\end{abstract}

Palabras clave: Modificación de las obligaciones, novación, subrogación, cesión de créditos, asunción de deudas, expromisión, delegación.

Abstract: This article aims to provide a civil legal perspective of the most important aspects of the modification of obligations in the Spanish Civil Code. First, conceptual difficulties are explained. Next, different aspects are examined, with special consideration of the problematic aspects. Finally, several lines of reform are pointed out.

Key words: modification of the obligations, novation, subrogation, assignment of credits, assumption of debt, expromision, delegation.

SUMARIO. I. INTRODUCCIÓN. II. LA NOVACIÓN. III. LA MODIFICACIÓN DE LA OBLIGACIÓN POR CAMBIO DE ACREEDOR. 3.1 Subrogación. 3.2 Cesión de créditos. IV. LA MODIFICACIÓN DE LA OBLIGACIÓN POR CAMBIO DE DEUDOR. 4.1. Asunción de deuda. 4.2. Expromisión. 4.3 Delegación. V. CONCLUSIÓN.

\section{INTRODUCCIÓN}

La obligación nace para ser cumplida, es decir, para extinguirse a través de su debido cumplimiento. Sin embargo, es posible que entre el nacimiento y la extinción de la obligación ésta sufra vicisitudes que impliquen ciertos cambios en la misma. Precisamente por ello la doctrina italiana ${ }^{1}$ ha acuñado la idea de vicisitud (vicenda), que vincula, en sentido estricto, al cambio o

${ }^{1}$ Destacadamente BETTI, Emilio. Teoría general de las obligaciones. (Traducción de DE LOS MOZOS). Madrid, 1970, Tomo II, págs. 185 y ss. y RESCIGNO, Pietro. Studi sull accollo. Milano, 1958, págs. 13 y ss. 
modificación de la obligación y a los efectos jurídicos que dicha alteración produce.

Aparece así el concepto de modificación de la obligación que, como enseña $\mathrm{BETTI}^{2}$, "designa una situación jurídica concerniente a los sujetos o al objeto, la cual sobreviene durante la vida de la relación jurídica, alterando la situación preexistente y señalando una nueva fase en el desenvolvimiento de la obligación" y que más sintéticamente conceptúa LACRUZ ${ }^{3}$ como "la alteración o cambio de alguno de los elementos estructurales o funcionales de la obligación que permita, empero, la subsistencia de la misma relación".

De este modo, la elasticidad de una obligación se mide cuanto más modificación admite sin provocar la extinción de la misma. La mutación puede operarse por voluntad privada y también por ley (v. gr., subrogación legal o transmisión judicial de los créditos). Por eso se dice que la modificación es siempre un hecho objetivo ${ }^{4}$. Lo más habitual es que se determine por los propios sujetos de la obligación, pero también puede ser consecuencia de otros hechos o incluso de imposición legal como acabamos de notar. Como efecto supone la pervivencia de la misma obligación que se mantiene junto a la alteración producida.

Siguiendo a DÍEZ-PICAZO ${ }^{5}$, es posible agrupar los diversos tipos o formas de modificación obligacional en los siguientes grupos:

1) Modificación subjetiva, por cambio de alguno de los sujetos de la obligación y que se halla prevista en el $1.203,2^{\circ}$ y $3^{\circ} \mathrm{CC}$. Incluye los supuestos de sustitución de alguno de los sujetos iniciales por otro diferente (cambio de acreedor o deudor), la agregación o supresión de sujetos y la alteración del régimen jurídico que regula las relaciones de los diferentes sujetos cuando éstos son múltiples o varios (mancomunidad, solidaridad).

2) Modificación objetiva, que es la que afecta al objeto de la obligación (art. 1.203, $1^{\circ} \mathrm{CC}$ ). Puede operarse un cambio de la naturaleza de la obligación, sustituyendo la prestación por otra (v. gr. obligaciones facultativas), un aumento o reducción de la prestación o, en fin, la plena concreción de la prestación cuando ésta no estaba totalmente determinada (como sucede en las obligaciones alternativas).

3) Modificación circunstancial, que afecta a las determinaciones accesorias de la obligación o de su ejecución y que el art. $1.203,1^{\circ} \mathrm{CC}$ deno-

\footnotetext{
${ }^{2}$ BETTI, op. cit., págs. 185-186.

${ }^{3}$ LACRUZ BERDEJO, José Luis. Elementos de Derecho civil. Derecho de Obligaciones. Vol. I. Barcelona, 1985, págs. 445 y ss.

${ }^{4}$ ALBALADEJO GARCIA, Manuel. Derecho civil, II, 1. Barcelona, 1980, pág. 333. PUIG FERRIOL, Luis y otros. Derecho de obligaciones, responsabilidad civil, teoría general de la persona. Madrid, 1996, pág. 365.

${ }^{5}$ DÍEZ-PICAZO, Luis. Fundamentos del Derecho civil Patrimonial. Tomo II. Madrid, 2008, pág. 955.
} 
mina alteración de las "condiciones principales" de la obligación (v. gr. tiempo o lugar).

4) Modificación funcional, cuando el cambio altera la función económicojurídica de la obligación tal y como fue configurada originariamente por las partes (a.e. se concede un permiso al depositario para usar de la cosa depositada, transformándose la obligación en comodato). Esta modalidad no está prevista directamente en el art. 1.203 CC pero, dado que el cambio de la causa implica necesariamente una alteración de la prestación, se puede reconducir al número $1^{\circ} \mathrm{del}$ art. $1.203 \mathrm{CC}$.

5) Modificación del contenido de la obligación que incide en su régimen jurídico, mediante la supresión, agregación o alteración de las reglas que rigen los derechos y deberes de las partes, y también admitida en el número $1^{\circ} \mathrm{del}$ art. $1.203 \mathrm{CC}$.

El Código civil no contiene una regulación completa y ordenada de la modificación de las obligaciones, regulación que por otra parte acomete conjuntamente con la extinción de las mismas (arts. 1.156 y ss.). Además, del examen de los diversos tipos de variaciones se desprende que este fenómeno, como vicisitud accidental de aquélla, no se sitúa en un plano de igualdad respecto de la constitución o extinción de la obligación. Éstos últimos son momentos necesarios, mientras que la modificación es un accidente posible aunque no imprescindible. Ello quizás explicaría la escasa y defectuosa regulación que el Código civil realiza respecto de la presente figura.

Por otra parte, debe notarse que si bien los elementos estructurales de la obligación descritos en el art. 1.203 CC pueden ser modificados -sujetos pasivo y activo, así como el objeto y condiciones principales- algunos autores ${ }^{6}$ han defendido que no todos tienen la misma jerarquía, por lo que hay elementos determinantes de la identidad de la obligación - p. ej., el deudor ${ }^{7}-$ de tal forma que su modificación comporta una novación extintiva, es decir, el cambio de la primitiva obligación por una nueva. Se trata, por tanto, de decidir en algunos casos problemáticos si el cambio es una mera modificación de la obligación anterior y que subsiste con su peculiar régimen jurídico o, por el contrario, se ha producido la extinción de aquélla y su sustitución por una nueva con un régimen jurídico ex novo, con las trascendentales consecuencias que ello tendría, por ejemplo, a efectos de mantenimiento de las garantías originarias o continuación de la prescripción ya iniciada. El problema, como acertadamente concluye DÍEZ-PICAZO ${ }^{8}$, no puede recibir una respuesta unívoca que posea carácter general, probablemente porque las vicisitudes modi-

${ }^{6}$ BADOSA COLL, Ferran. Dret d'Obligacions. Barcelona. 1990, pág. 229.

${ }^{7}$ Sin embargo, esta cuestión no es pacífica ni tampoco se plantea claramente en el Código ya que, como luego se verá, coinciden objetivamente los supuestos que pueden derivar en un cambio no extintivo o en una verdadera extinción de la obligación primitiva.

${ }^{8}$ DÍEZ-PICAZO, op. cit., pág. 958. 
ficativas no se presentan con carácter homogéneo, sino con una notable variedad de especies y subespecies.

\section{LA NOVACIÓN}

Una de las cuestiones más polémicas acaecidas tras la publicación de nuestro Código civil ha sido la referida al deslinde entre novación y modificación de la obligación. El Código contiene una regulación confusa de la novación en la que se mezclan ambas figuras. Por un lado, la novación aparece dentro de las causas de extinción de las obligaciones, tal y como la reputa el art. 1.156 CC y ubica en dicha sede (arts. 1.203-1.213 CC). Por otro lado, el artículo 1.203 CC, que principia su régimen legal, indica que "las obligaciones pueden modificarse [...]".

La novación nace en el Derecho romano clásico como único procedimiento de modificación de una obligación, y consiste en la sustitución de una obligación antigua que se extingue por otra nueva. Así lo resumió GAYO señalando que "novationem tollitur obligatio". Por tanto, la novación siempre era extintiva. Sin embargo, como ha estudiado SANCHO REBULLIDA ${ }^{9}$, la novación no era una institución, sino que la única institución propiamente dicha que interviene es la de la stipulatio. La novación era el efecto de una estipulación (stipulatio) mediante la que se introduce alguna novedad (aliquid novi) en la obligación preexistente y producía, de manera automática, el efecto novatorio por la incompatibilidad entre ambas obligaciones.

En el Derecho romano justinianeo el efecto novatorio ya no dependerá de la forma, al desaparecer la stipulatio, sino de la intención expresa de novar. Su evolución posterior sigue los pasos del concepto de obligación, por lo que se va patrimonializando progresivamente hasta ser considerado como un bien puramente económico que puede ser también objeto de modificación sin que implique extinción. El Código civil francés refleja ambas tendencias: de una parte, regula la novación al modo romano (art. 1.271); de otra, en el artículo siguiente admite la delegación impropia y la cesión de créditos. El punto final de esta evolución lo constituye el BGB, que ignora la novación y sólo regula el contrato de modificación.

De este modo, nuestro Código civil recoge la novación clásica romana que reputa la novación como un modo de extinción de las obligaciones y que además ubica en la Sección 6 ${ }^{\mathrm{a}}$ del Capítulo IV del Título I del Libro IV, Capítulo que se intitula precisamente "De la extinción de las obligaciones". Pero también admite la novación modificativa en el primer precepto que disciplina la figura, al recoger en el artículo 1.203 que "Las obligaciones pueden modificarse: $1^{\circ}$ Variando su objeto o sus condiciones principales. $2^{\circ}$ Sustituyendo

\footnotetext{
${ }^{9}$ En ALBADALEJO (dir). Comentarios al Código civil y Compilaciones forales. XVI, $1^{\circ}$. Madrid, 1980, pág. 499.
} 
la persona del deudor. $3^{\circ}$ Subrogando a un tercero en los derechos del acreedor". Pero además, el art. 1.204 recoge el carácter excepcional de la novación extintiva, al establecer que "Para que una obligación quede extinguida por otra que la sustituya, es preciso que así se declare terminantemente, o que la antigua y la nueva sean de todo punto incompatibles".

Por ello, resultan acertadas las críticas que la doctrina ${ }^{10}$ objeta al Código, entre las que destaca aquella referida al hecho de que en el breve articulado de esta Sección (los once artículos 1.203-1.213) se regulen conjuntamente y se mezclen varias figuras distintas, con la consiguiente confusión conceptual y diversidad terminológica. Se reglamentan a la par las variaciones en el contenido y el cambio de acreedor y de deudor, tanto en sus respectivas versiones extintivas como modificativas, por lo que no se logra la pretensión de lograr una regulación sencilla y unitaria, resultando a la postre que los conceptos no quedan delimitados con suficiente claridad.

En la actualidad, la doctrina mayoritaria y la jurisprudencia ${ }^{11}$ han deslindado claramente ambas modalidades de novación:

a) La novación propia o extintiva, en la que la modificación de alguno de los elementos de la obligación provoca la extinción de la obligación primitiva y su sustitución por otra nueva. Es la modalidad contemplada en el art. 1.156 y a la que también aluden los arts. 1.204 y 1.207 CC.

b) La novación impropia o modificativa, caracterizada por el hecho de que la alteración de alguno de los elementos de la obligación no supone su extinción, sino su mantenimiento con la modificación. A ella se refieren el art. 1.203 y los arts. 1.209 y siguientes del Código.

En relación con esta distinción, cabe señalar que únicamente se produciría la extinción cuando se cumpla uno de los criterios establecidos en el art. 1.204: "Para que una obligación quede extinguida por otra que la sustituya, es preciso que así se declare terminantemente, o que la antigua y la nueva sean de todo punto incompatibles". La extinción por voluntad terminante recoge el animus novandi del Derecho romano justinianeo y en principio no plantea demasiados problemas prácticos, si bien debe tenerse en cuenta la existencia de una consolidada línea jurisprudencial ${ }^{12}$ que postula que la novación extintiva no se presume y el beneficio de la duda favorece a la parte que contradice la

\footnotetext{
${ }^{10}$ Un panorama de la cuestión puede encontrarse en CRISTÓBAL MONTES, Ángel. " $\mathrm{La}$ llamada novación modificativa en el Derecho civil español”. Temis, núm. 33-36. Zaragoza, 1973/74, págs. 737 a 742. También en Revista crítica de derecho inmobiliario, 1973, pág.1162.

${ }^{11}$ Así SSTS de 12 marzo de 2009 (Ar. 2009,1645), de 3 noviembre 2004 (Ar. 2004, 6869), de 20 febrero de 2002 (Ar. 2002,1366), de 17 septiembre 2001 (Ar. 2001,7479), de 26 julio (Ar. 1997,5953) o de 27 noviembre 1990 (Ar. 1990, 9056), entre otras.

${ }^{12}$ Entre otras, SSTS de 28 de diciembre de 2000 (Ar. 2000, 10382), 23 de marzo de 2001 (Ar. 2001, 4757), 27 de septiembre de 2002 (Ar. 2002, 7877) y 4 de marzo de 2005 (Ar. 2005, 1778).
} 
misma. La extinción por incompatibilidad entre obligaciones responde a la concepción romana clásica y ha sido objeto de un importante debate doctrinal. La posición mayoritaria, liderada por DÍEZ-PICAZO ${ }^{13}$ y HERNÁNDEZ $\mathrm{GIL}^{14}$, argumenta que la incompatibilidad existe cuando las obligaciones pertenecen a tipos distintos, de modo que la alteración provoca un cambio del régimen jurídico al que estaba sometida globalmente la obligación. El Tribunal Supremo no ha establecido criterios generales al respecto, sino que actúa prudentemente caso por caso ponderando las circunstancias concurrentes. Fuera de estos supuestos estaríamos ante una mera modificación con subsistencia de la obligación.

Los efectos típicos y genéricos de la novación aparecen previstos en los artículos 1.207 ("Cuando la obligación principal se extinga por efecto de la novación, sólo podrán subsistir las obligaciones accesorias en cuanto aprovechen a terceros que no hubiesen prestado su consentimiento ") y $1.208 \mathrm{del}$ Código ("La novación es nula si lo fuere también la obligación primitiva, salvo que la causa de nulidad sólo pueda ser invocada por el deudor, o que la ratificación convalide los actos nulos en su origen").

En cuanto a la novación modificativa, lógicamente sólo produce la simple modificación de la obligación pero sin que se vean alteradas las obligaciones accesorias, salvo que la novación amplíe el contenido de la obligación, haciéndola más gravosa, en cuyo caso exigirá el consentimiento del tercero acudiendo a la regla del art. 1.207 CC.

Nos detenemos a continuación en aquellas vicisitudes modificativas especialmente relevantes por el elemento al que afectan y por su regulación expresa como categorías perfectamente identificables.

\section{LA MODIFICACIÓN DE LA OBLIGACIÓN POR CAMBIO DE ACREEDOR}

Una modalidad frecuente de alteración obligacional se produce con el cambio del acreedor produciendo una modificación subjetiva con un nuevo acreedor. Hoy es una cuestión pacífica al haberse superado la concepción romana de la obligación como un vínculo personal, formado esencialmente intuito personae que no permitía, como es sabido, mutaciones subjetivas salvo en la sucesión hereditaria.

El cambio del titular del derecho de crédito puede operarse bien con la subrogación en el mismo (I) o con la cesión del crédito (II).

\footnotetext{
${ }^{13}$ DÍEZ-PICAZO, op. cit., pág. 964.

${ }^{14}$ HERNÁNDEZ GIL, Antonio. "El ámbito de la novación modificativa”. RDP, 1961, págs. $797 \mathrm{y}$ ss.
} 


\subsection{Subrogación}

Conforme a lo dispuesto en el art. 1.212 del Código civil, "La subrogación transfiere al subrogado el crédito con los derechos a él anexos, ya contra el deudor, ya contra los terceros, sean fiadores o poseedores de las hipotecas". Debe señalarse la defectuosa redacción del último inciso, que debería referirse a los "propietarios de las fincas hipotecadas".

Esta forma de modificación subjetiva de la obligación puede conceptuarse como "aquella forma de pago en la que un tercero paga una deuda ajena al acreedor, sin extinguirse la obligación, convirtiéndose así en nuevo acreedor del antiguo y verdadero deudor".

El pago que hace ese tercero extingue el derecho de crédito del acreedor pero no la obligación, que permanece idéntica, ya que tan sólo se produce un cambio en la persona del primitivo acreedor, convirtiéndose quien paga en el nuevo acreedor, razón por lo que se admite entre los tipos de la llamada novación impropia o modificativa.

En definitiva, la subrogación es un subingreso de un nuevo acreedor en lugar del antiguo mediante el pago del crédito, que deviene titular del mismo en idénticas condiciones y con los mismos privilegios y garantías personales y reales que disfrutaba el acreedor subrogado. Por ello, se trata de una forma de sucesión a título particular e intervivos, simétrica a la asunción de deuda.

No obstante, es preciso distinguirla de la cesión de créditos con la que puede confundirse en su modalidad de subrogación convencional. La diferencia es clara partiendo de la finalidad de cada una de las categorías: en la subrogación se procura atender al interés del subrogado en recuperar en vía de regreso un desembolso patrimonial que ha efectuado al acreedor satisfecho. Por eso se pone el acento en el hecho del pago realizado al definir la figura. En cambio, la cesión voluntaria del crédito a que se refieren los arts. 1.526 y ss. del Código civil es un negocio jurídico de transmisión y cumple una función económica de circulación de los créditos.

La subrogación admite dos modalidades:

a) Subrogación presunta o legal, que se establece expresamente por el Código o por otras leyes y se produce sin necesidad de que el acreedor o el deudor consientan. Con carácter general, los supuestos se enuncian en el art. 1.210. Además, algún supuesto concreto puede encontrarse en los arts. $145.2,1.839$ o los arts. 1.158 y $1.159 \mathrm{CC}$, con las peculiaridades que cada uno de ellos incorpora. Observa acertadamente BERCOVITZ RODRÍGUEZ-CANO ${ }^{15}$ que, aunque el precepto habla de "presunción", se trata en rigor de una subrogación ope legis sin necesidad del consentimiento del acreedor, que no podrá oponerse a ella.

b) Subrogación expresa o convencional, que se produce cuando no concurren los requisitos legales mediante un acuerdo entre el primitivo

${ }^{15}$ En ALBALADEJO (dir), Comentarios... op. cit., XVI, 1º., pág. 28. 
acreedor y el nuevo acreedor subrogado (art. 1.209). La subrogación convencional no requiere, en cambio, el consentimiento del deudor. Por excepción, el art. 1.211 permite al deudor hacer la subrogación sin consentimiento del acreedor, cuando para pagar la deuda haya tomado prestado el dinero en escritura pública, haciendo constar en ella su propósito y expresando en la carta de pago la procedencia de la cantidad pagada. Este precepto es desarrollado por Ley 2/1994, de 30 de marzo, sobre subrogación y modificación de préstamos hipotecarios, modificada recientemente por Ley 41/2007, de 7 diciembre, por la que se modifica la Ley 2/1981, de 25 de marzo, de Regulación del Mercado Hipotecario y otras normas del sistema hipotecario y financiero, de regulación de las hipotecas inversas y el seguro de dependencia y por la que se establece determinada norma tributaria. La Ley disciplina la subrogación en los préstamos hipotecarios otorgados por Entidades financieras y permite una mayor movilidad que facilita a los prestatarios aprovecharse de las mejores condiciones del mercado.

El efecto de la subrogación es transferir al subrogado el derecho de crédito con todos los derechos a él anexos que hubiere contra el deudor, fiadores o poseedores de hipotecas (art. 1.212 CC). Si el acreedor, como consecuencia del pago, únicamente hubiere cobrado parte de su crédito, puede después cobrar el resto de su crédito con preferencia al que se hubiere subrogado en su lugar en virtud del pago parcial de ese crédito (art. 1.213 CC).

\subsection{Cesión de créditos}

Constituye el segundo de los procedimientos por los que se produce el cambio de acreedor y puede definirse como "el acuerdo de voluntades entre el antiguo y el nuevo acreedor (cedente y cesionario) en virtud del cual la titularidad del derecho de crédito se transmite del primero al segundo, quien se subroga o subentra en la posición jurídica del primitivo acreedor"16.

Hoy se trata de una figura pacífica y frecuente lo cual ha sido consecuencia de la evolución ya aludida de la institución obligacional. En efecto, en el Derecho romano al concebir la obligatio como un vínculo eminentemente personal difícilmente resulta admisible que el poder del acreedor pueda ser transmitido a otro. Además, la dureza de sus métodos ejecutivos acentúa el riesgo que para el deudor significa el cambio de acreedor. Por ello, JUSTINIANO prohibió la cesión a potentiores, a personas más poderosas que el cedente (C., 2,13,2), prohibición que llega a las Partidas $(3,7,16)$. Sin embargo, las necesidades del tráfico jurídico impulsaron progresivamente la admisión de esta operación, que llega a ser perfectamente factible en la época

${ }^{16}$ PANTALEÓN PRIETO, Fernando. “Cesión de créditos”. ADC, 1988, 1033. 
postclásica $^{17}$. En la Edad Media la cesión se desarrolló principalmente en el ámbito del Derecho mercantil, particularmente con los títulos a la orden y al portador, para culminar en su reconocimiento pacífico con la Codificación, y que recoge nuestro art. 1.112 CC: "Todos los derechos adquiridos en virtud de una obligación son transmisibles con sujeción a las leyes, si no se hubiese pactado lo contrario".

El Código civil regula la transmisión de "créditos y demás derechos incorporales" en los arts. 1.526 a 1.537 que integran el Capítulo VII del Título IV del Libro IV, como una modalidad especial de la compraventa. La doctrina, de modo unánime, ha formulado diversas críticas acerca de la rúbrica y ubicación. También se reprocha al legislador que desconozca la posibilidad de que un crédito puede cederse por cualquier título oneroso o gratuito, como donación, permuta o dación en pago, entre otros, aunque la modalidad habitual de la cesión sea la propia compraventa.

Por lo que se refiere a los requisitos de la cesión como tal, son los siguientes:

1) La cesión, con carácter general, es resultado de un acuerdo entre el acreedor primitivo (cedente) y el nuevo acreedor (cesionario). El deudor cedido no es parte en el acuerdo, ni la cesión precisa su consentimiento. El deudor no es sujeto de la cesión, aunque ésta no le perjudicará hasta que la conozca, puesto que no parece que tenga interés alguno en relacionarse con un acreedor en vez de con otro, razón por la cual no se requiere su consentimiento. Sin embargo, esta idea no puede absolutizarse puesto que, por ejemplo, un acreedor puede ser menos paciente, más estricto o menos colaborador. Además, la jurisprudencia subraya la imposibilidad de empeorar las condiciones de ningún deudor por una cesión inconsentida. Indudablemente, el deudor responde ante el cesionario de la misma obligación, no de una obligación distinta (STS 15 noviembre 1990), porque la cesión no extingue el crédito (STS 22 febrero 1994).

2) En principio, son susceptibles de cesión todos los créditos (art. 1.112), salvo aquellos estrictamente personales, aquellos en los que exista prohibición legal expresa (v. gr. alimentos) o, en fin, que exista pacto contrario a la misma.

3) En cuanto a la forma, el Código no exige una formalidad determinada, por lo que son aplicables las reglas generales. De este modo, para que la cesión produzca efectos contra terceros, según el art. 1.526, "la cesión de un crédito, derecho o acción no surtirá efecto contra tercero sino desde que su fecha deba tenerse por cierta [en escritura pública] en conformidad a los arts. 1.218 y 1.227 ", añadiendo que "si se refiere a un inmueble, desde la fecha de su inscripción en el Registro".

${ }^{17}$ Vid. BONFANTE, Pietro. Historia del Derecho romano. Traducción por José Santa Cruz Teijeiro. Madrid, 1944, pág. 289. 
La notificación se configura como una norma de protección del deudor cedido $^{18}$. Desde la Sentencia de 27 febrero 1891, el Tribunal Supremo defiende que la cesión puede hacerse válidamente sin conocimiento previo del deudor, como lo ratifican numerosas sentencias entre las que pueden citarse las de 15 abril 1924, 12 mayo 1932, 28 octubre 1957, 5 noviembre 1974, 16 octubre 1982, y que, por tanto, el consentimiento del deudor no es requisito que afecte a su existencia (STS 5 noviembre de 1993, 13 junio 1997). Dicho consentimiento, en cambio, es valorado como requisito de eficacia para que se obligue con el nuevo acreedor, mientras que la puesta en conocimiento (notificación) sólo tiene la finalidad de impedir que se produzca su liberación (SSTS 16 octubre 1982, 24 octubre 1984, 27 septiembre 1991, 24 febrero 1993, 14 julio 1994, de la Sala $3^{\text {a }}$ S. 31 octubre 1992), aunque no siempre se precisa con claridad en los fallos la diferencia entre la inexistencia de la cesión o su ineficacia, sea de créditos o de contratos.

El efecto de la cesión es lógicamente la transmisión del crédito con sus accesorios, como señalan los arts. 1.528 CC o 149 LH. La posición del deudor cedido permanece inalterada, pudiendo oponer al nuevo acreedor las excepciones que tuviera contra el antiguo y, además, las que tuviera con el nuevo. No obstante, si el deudor consintió la cesión, pierde las excepciones personales que tenía frente al acreedor cedente. Asimismo, dado que la transmisión del crédito no requiere ni el consentimiento ni el conocimiento del deudor, según el art. 1.527, "el deudor, que antes de tener conocimiento de la cesión satisfaga al acreedor [cedente], quedará libre de la obligación".

Por último, debemos hacer referencia al régimen de responsabilidad del cedente, que el Código disciplina en los arts. 1.529 y 1.530 para las cesiones onerosas. Para las gratuitas resulta aplicable el art. 638, en cuya virtud el cedente no responde, salvo si se trata de una donación onerosa, en cuyo caso "responderá el donante de la evicción hasta la concurrencia del gravámen". Por lo que se refiere a las cesiones onerosas, el Código distingue si el cedente obró de buena o mala fe:

a) Si el cedente es de buena fe, responde de la existencia y legitimidad del crédito, la llamada veritas nominiis, es decir, que en el momento de la cesión, el crédito existe, pertenece al cedente y es exigible en las condiciones que resultan del propio crédito. Se exceptúa el caso en que el crédito se haya vendido como dudoso (art. 1.529.1 CC). No responde, en cambio, de la solvencia del deudor, la bonitas nominiis, a menos de se haya pactado expresamente, o que la insolvencia fuese anterior y pública ${ }^{19}$. Esta responsabilidad comprende el precio recibido, los gastos del contrato y cualquier otro pago legítimo hecho.

${ }^{18}$ Vid. PANTALEÓN PRIETO, Fernando. Comentario del Código civil. Madrid, 1993, págs. 1025-1027.

${ }^{19}$ Sin embargo, el art. 1.206 CC se refiere también a la insolvencia conocida del deudor al delegar su deuda. 
b) Por el contrario, si el cedente es de mala fe, responde de la existencia y legitimidad del crédito así como de la solvencia del deudor, y el contenido de la responsabilidad alcanza a todos los gastos y todos los daños y perjuicios.

Finalmente, existen reglas específicas para la duración de la responsabilidad en defecto de pacto expreso (art. 1.530), la venta de la herencia (art. 1.531), la cesión de la totalidad de ciertos derechos, rentas o productos (art. 1.532), créditos litigiosos (art. 1.535) o la cesión de créditos hipotecarios (art. $149 \mathrm{LH})$.

\section{LA MODIFICACIÓN DE LA OBLIGACIÓN POR CAMBIO DE DEUDOR}

La modificación obligacional por cambio de deudor no ha resultado tan pacífica como el supuesto anterior. En esta polémica doctrinal se ha argumentado que no puede hablarse stricto sensu de «transmisión», pues la «transmisión» es un acto de traslación de poderes activos, y sólo de éstos. Además, es claro que el cambio de la persona del deudor interesa especialmente al acreedor y a los fiadores y avalistas, ya que sus condiciones personales de seriedad y de moralidad, así como sus condiciones económicas de solvencia y responsabilidad son decisivas.

Todo lo cual se complica todavía más por la falta de acuerdo en la terminología a emplear (es habitual encontrar autores utilizando, con significados distintos, los términos de delegación, expromisión y asunción de deuda), y por las discusiones teóricas acerca de figuras afines (destacadamente, respecto al Código civil, la novación, y más concretamente en el aspecto de si cabe o no la novación modificativa). De ahí que no le falte razón a DÍEZ-PICAZO ${ }^{20}$ cuando afirma que "todo este debate tiene mucho de nominalismo y de logomaquia", y aconseja una aproximación tópica y funcional a la figura, para después obtener, en su caso, las conclusiones teóricas procedentes.

La alteración de la obligación por cambio de deudor resulta impensable en el Derecho romano, al significar una concepción no personal sino patrimonial del crédito, y ha sido acuñada por la doctrina alemana en la segunda mitad del siglo XIX ${ }^{21}$. En efecto, el cambio de un deudor por otro se produce en el Derecho romano mediante la stipulatio novatoria o novación, que como se vio, supone la extinción de una obligación y el nacimiento de otra nueva en su lugar, reafirmándose así la intransmisibilidad activa y pasiva intervivos de las obligaciones en este Derecho. Junto a esta figura principal, la mayor parte de la doctrina romanística admite, para determinadas etapas del desa-

\footnotetext{
${ }^{20}$ Op. cit., pág. 1015.

${ }^{21}$ Vid. en detalle VON THUR, Andreas. Tratado de las Obligaciones, traducido del Alemán por W. Roces, Tomo II. Madrid, 1934, pág. 147 y siguientes.
} 
rrollo de este Derecho, otra figura con el mismo efecto, que se perfeccionaba mediante un contrato literal o escrito y que recibió el nombre de nomina transcripticia. Al fin, el sentido práctico de la mentalidad romana y las necesidades del comercio lograron desarrollar otros medios indirectos para lograr el mismo resultado práctico que el cambio de deudor; entre estos medios destaca la figura que se conoce con el nombre de cognitor o procurator in rem suam ${ }^{22}$.

Junto a la novación, el Derecho romano conoció la figura de la delegatio (delegare), con múltiples significados en las fuentes y que tenía una utilidad mucho más amplia que la que ahora nos ocupa, es decir, permitir a un tercero hacerse cargo de una deuda ajena mediante novación. En las fuentes encontramos una definición que se ajusta a esta orientación y que nos suministra Ulpiano en D. 46, 2, 11: "Delegar es dar al acreedor, o a aquel para quien se hace la autorización, otro deudor en lugar de uno mismo. La delegación se hace por medio de una estipulación o por la litiscontestación" ${ }^{23}$. El delegado se hará cargo de la deuda que hasta entonces recaía en el delegante, quedando éste libre de la misma en cuanto se obtenga la anuencia del delegatario. Como consecuencia de ello, queda extinguida la primera obligación y nace otra nueva en su lugar a cargo del delegado, todo ello consecuencia de la estipulación novatoria.

En cambio, es ajeno el Derecho romano al concepto de expromisión tal y como se configuró posteriormente por los Glosadores y los Comentaristas (y como lo conocemos hoy), es decir, como un acuerdo entre el acreedor y un tercero para que éste sustituya al deudor. Dice DÍEZ-PICAZO ${ }^{24}$ que en el Derecho romano se utilizaban los términos expromissio o expromittere para aludir a una promesa hecha por persona distinta al anterior promitente o hecha a persona distinta del beneficiario de una promesa anterior, lo que podía conllevar tanto un cambio de deudor como de acreedor, aunque también se utilizaba en supuestos distintos. En sentido parecido, Antonio $\mathrm{MASI}^{25}$, aunque

${ }^{22}$ En realidad, todos los señalados son medios indirectos para lograr un efecto análogo a la transmisibilidad de las obligaciones: ARIAS RAMOS, José y ARIAS BONET, Juan Antonio. Derecho romano. Madrid, 1986, II, pág. 703 y FUENTESECA, Pablo. Derecho Privado romano. Madrid, 1978, pág. 191.

${ }^{23}$ D. 46, 2, 11, 1. Casi todas las referencias a la delegación las encontramos en el libro XLVI, título $2^{\circ}$, del Digesto, bajo la denominación "las novaciones y las delegaciones", donde se habla de delegación en relación a la novación (expresamente a la delegación tan sólo se refieren las leyes $4,11-13,17,19$ y 33 , de un total de treinta y cuatro que componen este título). Alguna otra referencia muy breve se encuentra en las Institutiones de Gayo (Gai. 3 , 130) y en las de Justiniano (Inst. 3, 29). Pero no hay verdadera novación en la llamada novación necesaria (D. 46, 2, 29; Paul.,24 quaest.), es decir, el efecto de la litis-contestatio consistente en sustituir la relación obligatoria por la relación procesal: Véase D'ORS, Álvaro, Derecho Privado romano. Pamplona, 1991, § 440, págs. 495-496. Sí entienden que se puede hablar de efecto novatorio TORRENT, Armando. Manual de Derecho Privado romano. Madrid, 1993, pág. 375 y GARCÍA GARRIDO, Manuel Jesús. Derecho Privado romano. Madrid, 1985, pág. 137.

${ }^{24}$ DÍEZ-PICAZO, op. cit., págs. 1015 y 1016.

${ }^{25}$ MASI, Antonio, voz “Expromissio”, en Novissimo Digesto Italiano 6 (1981), pág. 1092. 
matizando que los términos utilizados en las fuentes son expromittere y expromissor (no expromissio), apunta que es utilizado para designar indistintamente la novación subjetiva y la objetiva. Modernamente, la expromisión se caracteriza, frente a los otros negocios jurídicos admitidos tradicionalmente para producir la asunción de una deuda ajena por un tercero, por tratarse de un acuerdo bilateral entre el acreedor y el tercero-asumente, es decir, sin intervención del deudor antiguo, lo que sustantiva a esta figura frente a la delegación.

La evolución posterior a lo largo del Derecho intermedio, a partir del brocado in delegatione sempter inest novatio, reputa la expromisión y la delegación como formas de novación. Esta concepción fue acogida por POTHIER y el Código francés. Sin embargo, a mediados del siglo XIX la doctrina alemana sometió a una profunda crítica el dogma de la intransmisibilidad pasiva de las obligaciones. De este modo, la evolución posterior del fenómeno del cambio de deudor está marcada por dos grandes líneas de influencia:

a) De una parte está la tradición romana de la novatio y la delegatio, recogida por la Escuela del Derecho Natural racionalista en los siglos XVII y XVIII y que encontrará continuidad en Robert Joseph POTHIER $^{26}$. Sus exposiciones constituirán la base de los artículos 1.271 a 1.281 del Code francés y también del Codice italiano de 1865 (artículos 1.267 a 1.278).

b) De otra parte, y en sentido opuesto, se posiciona la pandectística alemana a partir de mediados del siglo XIX con su crítica al dogma de la intransmisibilidad pasiva de las obligaciones. Ante todo, fue DELBRÜCK quien abordó más profundamente el estudio de este fenómeno y acuñó el término "Übernahme" o "Schuldübernahme", a partir del cual se construyó la teoría de la "Singularsuccession in Schulden" ${ }^{\text {"27 }}$. La obra de este tratadista constituyó un intento de conciliar los principios romanos con la tradición germánica y las necesidades de la práctica, y la edificó sobre la distinción entre la obligación, entendida como un vínculo entre personas y como tal intransmisible (clara influencia romana), y los elementos activo (crédito, "Forderung") y pasivo (deuda, "Schuld"), que serían susceptibles de enajenación; en el caso de la deuda, por la sola voluntad de los deudores sucesivos y sin la intervención del acreedor. Esta dirección fue continuada por Bernhard WINDSCHEID ${ }^{28}$ y se materializó en gran medida posteriormente en

${ }^{26}$ POTHIER, Robert Joseph. Traité des obligations (edic. por Bernardi, Paris, 1805), II, nn. 546 ss., págs. 60 y ss.

${ }^{27}$ DELBRÜCK, Ernst Luther Berthold, Die Uebernahme fremder Schulden nach gemeinem und preussischen Rechte. Greifswald, 1853.

${ }^{28}$ WINDSCHEID, Bernhard. Die Singularsuccession in Obligationen. Ueberschau, Munich, 1853 y Zur Erinnerung an Berthold Delbrück en Kritische Überschau der deutschen Gesetzgebung und Rechtswissenschaft. Berlín, 1853. 
los $\S 414$ y ss. del BGB alemán y en los artículos 175 al 183 del Código suizo de 1911, así como en códigos más recientes como los artículos 595 al 600 del Código portugués de 1966.

El Código civil español, siguiendo en parte en este punto al Código civil francés (y al italiano de 1865, continuador de este último) regula el cambio de la persona del deudor como una de las posibles aplicaciones de la novación: la novación subjetiva por cambio del deudor.

A ella se refieren, según señala la doctrina dominante, los artículos 1.203.2..$^{\circ}$ y del 1.205 al $1.208 \mathrm{CC}$, siendo más dudosa la aplicabilidad del artículo 1.204 que, en nuestra opinión, debe quedar para la novación objetiva. En concreto, el artículo 1.203.2. ${ }^{\circ}$ recoge el cambio de deudor como una de las posibles formas mediante las cuales "las obligaciones pueden modificarse", el artículo 1.205 se refiere a la necesidad de concurrencia del consentimiento del acreedor para que se produzca el cambio de deudor, el artículo 1.206 recoge los posibles casos en que, si resultara insolvente el nuevo deudor, el acreedor podría dirigirse contra el que hasta entonces parecía liberado, el artículo 1.207 establece el régimen jurídico de las obligaciones accesorias ante la novación y el artículo 1.208, en fin, queda dedicado a los efectos que, sobre la nueva obligación, puede tener la nulidad de la antigua.

Tras la publicación del Código civil, la doctrina mayoritaria consideró que nuestro Código se inspiró en este punto en el Código civil francés, acogiendo la concepción tradicional, romano-napoleónica, de la intransmisibilidad de las deudas. Se invocan en este sentido el art. 1.203 CC, que habla de la sustitución de la persona del deudor como un caso de novación y el art. 1.207 , según el cual en la novación por cambio de deudor desaparecen las obligaciones accesorias de la obligación novada.

Sin embargo, la publicación en 1912 de la obra del profesor DE DIEGO sobre la transmisibilidad de las obligaciones ${ }^{29}$, en la que abogó decididamente por la transmisión sin novación y combatió las objeciones a la misma, permitió que nuestra doctrina fuera mostrándose partidaria a su admisión. Esta idea fue continuada por autores como VALVERDE, PÉREZ GONZÁLEZ y ALGUER o CASTÁN. Por su parte, el Tribunal Supremo desde la Sentencia de 22 de febrero de 1946 ha admitido esta modalidad siempre que sea consentida por el acreedor y esta línea perdura hasta hoy.

No obstante, un sector doctrinal ha venido objetando esta posibilidad, negando su paralelismo con el cambio de acreedor y destacando las diferencias entre ambas figuras. Ya en 1930 DE BUEN ${ }^{30}$ advirtió que, aunque se admita el cambio de deudor con el consentimiento del acreedor, los terceros que garanticen la primera deuda no seguirán garantizando al nuevo deudor, con lo

${ }^{29}$ DE DIEGO, Felipe Clemente. Transmisión de las obligaciones según la doctrina y la legislación española y extranjera: la transmisibilidad de las obligaciones. Madrid, 1912.

${ }^{30}$ DE BUEN, Demófilo. Derecho civil español común. Madrid, 1930, pág. 495. 
que se producen los mismos efectos que en la novación extintiva. También el mismo año don Federico DE CASTRO ${ }^{31}$ se opuso a la misma idea, afirmando que no existe en nuestro Derecho ningún caso de cesión de deuda que no haya de regirse por el art. 1.205 y ser considerada, por tanto, como novación.

En idéntica línea, COSSÍO ${ }^{32}$, ROCA SASTRE ${ }^{33}$ y LACRUZ LA $^{34}$ añaden que, desde un punto de vista dogmático, la deuda es un valor negativo, no susceptible de transmisión e indisociable del derecho del acreedor, de modo que lo único posible es que el acreedor consienta en recibir la prestación de otro deudor con lo cual se extingue una deuda y nace otra. Además, en un plano práctico, no puede defenderse la ficción de que la obligación no se altera, que se mantienen vigentes las garantías prestadas por terceros o que el nuevo deudor pueda oponer las excepciones del antiguo, lo cual, si se produce, será por un pacto expreso entre el acreedor y el nuevo deudor.

En definitiva, puede concluirse que si bien han desaparecido los obstáculos dogmáticos al principio de la modificación pasiva de la obligación, no puede sostenerse una correspondencia absoluta con el cambio de acreedor, ya que existen importantes diferencias que imponen un cierto componente novatorio en el fenómeno.

Volviendo ahora al Derecho positivo, el Código acepta dos modalidades de cambio de deudor, la delegación (art. 1.206) y la expromisión (1.205), aunque se ha consolidado la admisión de una tercera, la asunción de deuda, amparándose en el principio de autonomía de la voluntad (art. 1.255). Nos referimos, no obstante, a esta última en primer término.

\subsection{Asunción de deuda}

Se denomina asunción de deuda el hecho de la sustitución de un deudor por otro que asume la deuda del primero. Figura sobre cuya admisibilidad se ha dudado durante mucho tiempo, empero hoy es aceptada como forma característica de modificación de la relación obligatoria por sustitución del deudor, con fundamento en los argumentos a favor de los arts. 1.203.2, $1.204 \mathrm{y}$ 1.255 CC y ratificación jurisprudencial. También recibe la denominación de "contrato de asunción de deuda" 35 , contrato atípico que se rige por lo acordado

${ }^{31}$ DE CASTRO, Federico. "Cesión del arrendamiento y el subarriendo”. RGLJ, 136, 1930, pág. 143.

${ }^{32}$ COSSÍO, Alfonso. "La transmisión pasiva de las obligaciones a título singular”, $A A M N, 1,1945$, págs. 183 a 187.

${ }^{33}$ ROCA SASTRE, Ramón María. Estudios de Derecho Privado, volumen II. Madrid, 1948, págs. 294 a 301.

${ }^{34}$ LACRUZ, op. cit. vol. Il-I, págs. 293 y ss.

${ }^{35}$ Más detalladamente GARCÍA PORTERO, Roberto. A propósito de la asunción de deuda. Revista del Instituto de Derecho civil, n. ${ }^{\circ}$. Buenos Aires, Argentina, 1985, págs. $120-134$. 
entre las partes (antiguo y nuevo deudor), lo consentido por el acreedor y por las reglas generales de las obligaciones y contratos. Con ello se superaría la imposibilidad de que el deudor disponga de su posición jurídica.

Según la STS de 27 de junio de 1991, "la asunción de deuda, si bien reviste caracteres de negocio atípico, no obstante la referencia que el ordenamiento hace respecto a la misma, es perfectamente procedente y adecuada, según el artículo $1205 \mathrm{CC}$ y doctrina sostenida repetidamente por esta Sala. Mediante tal institución, el deudor originario viene a ser sustituido por el posterior que asume la deuda, en dimensión liberatoria, mediante el consentimiento del acreedor a esta mutación subjetiva en el pacto relacionante, operando, en caso de insolvencia del nuevo deudor, con los efectos que prevé el art.1206 CC" (vid. también STS. 27 junio 1991).

Aunque se acepta tanto la asunción liberatoria, desligándose el deudor originario de la relación, como cumulativa, cuando el antiguo deudor se mantiene vinculado a la relación obligatoria junto al nuevo, esta segunda modalidad se considera una excepción y debe aparecer con claridad en el correspondiente pacto.

\subsection{Expromisión}

Constituye el supuesto más sencillo de cambio de deudor, representativo de los principios generales de mutación subjetiva a los que antes aludíamos, en el que el acreedor tiene la iniciativa y toma la decisión de asumir un nuevo deudor. Se lleva a cabo en esta ocasión un convenio entre el acreedor y un nuevo deudor que libera al primitivo sin requerir consentimiento ni conocimiento de éste (art. 1.205). En consecuencia, el riesgo de insolvencia del nuevo deudor lo asume por completo el acreedor.

Lógicamente sólo en el caso de la denominada expromisión cumulativa el deudor primitivo seguiría vinculado al cumplimiento de la obligación.

\subsection{Delegación}

Figura más compleja y de gran predicamento en el ámbito bancario ${ }^{36}$, la delegación requiere de la intervención de tres sujetos: el deudor actual que es quien toma la iniciativa proponiendo su sustitución al acreedor al que "presenta" un nuevo deudor; éste que admite ocupar el lugar del deudor y el acreedor que ha de aceptar. En definitiva, se produce en virtud de acuerdo entre deudor antiguo y nuevo deudor por el que éste asume la deuda con consentimiento del acreedor. Hay delegación siempre que se suministra a una persona

\footnotetext{
${ }^{36}$ Más detalladamente véase ROIG GUERRERO, Francisco. "La delegación de deudas en el ámbito bancario”. X años de encuentros sobre Derecho bancario, 1996-1997, págs. 371-380.
} 
un valor cualquiera indirectamente a través de la persona a la que se ha dado orden de suministrarlo.

Es, por tanto, el mecanismo por el que una persona (delegante) da una orden o autoriza a otra (delegado) para que constituya una obligación o realice una prestación a favor de otra (delegatario) (STS de 27 de junio de 1991).

En el Código no se contempla la regulación de las relaciones internas entre delegante, delegado y delegatario, sino sólo el reparto de riesgos entre ellos, de lo que se ocupa el art. 1.206: el acreedor corre con el riesgo de insolvencia del nuevo deudor que ha aceptado, salvo que esta insolvencia fuera anterior, pública o conocida del deudor al delegar su deuda, en cuyo caso el primitivo deudor sigue vinculado a la obligación, esto es, teniendo en cuenta su mala fe. Se acepta, no obstante, que se origina una relación de cobertura entre delegante y delegado y una relación de valuta entre delegante y delegatario.

Se describe, por tanto, en el art. 1206 la delegación pasiva, aceptándose también una delegación activa, al amparo del art.1.203.3, en la que el acreedor delegante invita u ordena al delegado a convertirse en acreedor del delegatario.

Finalmente, debemos hacer una breve referencia a otras cuestiones vinculadas a los efectos y de aplicación a cualquiera de los supuestos de cambio de deudor que, sin embargo, están reguladas de forma poco clara o no se contemplan expresamente. Así ocurre en primer lugar con la pervivencia de las garantías otorgadas: aplicando las reglas generales del Derecho de obligaciones, debe señalarse que si las prestó un tercero, este deberá consentir el cambio de deudor para que se mantengan; si las prestó el anterior deudor, dependerá de si se asumen o no por el nuevo; y si las prestó el nuevo antes de asumir la deuda, si son reales subsisten y se extinguen en cambio las personales.

En segundo y último término debemos referirnos a la defensa del nuevo deudor, a las excepciones oponibles por él, nada se dice expresamente, pero cabe deducir que puede oponer las excepciones de carácter objetivo de la relación obligatoria, aquellas que afecten al medio a través del que se produjo el cambio de deudor y las que se originen en su relación con el acreedor a partir del cambio. No cabe, por el contrario, la oposición de excepciones puramente personales del primitivo deudor.

\section{CONCLUSIÓN}

El Derecho de obligaciones que se incorporó al Código civil no fue una de sus partes más logradas. Fundamentalmente, el Código se limitó a tomar la base del Proyecto de 1851 y, por esta vía, el modelo del Código civil francés, con algunas conocidas excepciones como el rechazo de la transmisión consensual de la propiedad. Sobre estos cimientos los codificadores tomaron algunos elementos del Código civil italiano de 1865, del argentino y de las 
Notas de Dalmacio Vélez Sársfield y, en fin, del Anteproyecto de Laurent. Se produjo así un mixtum que muchas veces no resulta fácil de descifrar. Además, muchos de estos preceptos estaban tomados de épocas anteriores por lo que no resultaron satisfactorios para dar respuesta a los acontecimientos económicos que se estaban produciendo y se iban a originar poco después.

En este trabajo hemos señalado los diversos problemas que presenta la figura de las modificaciones obligacionales, resultando especialmente patente cómo los codificadores no pusieron aquí sus máximos esfuerzos, por lo que se requiere acometer su reforma. En primer lugar, es necesario deslindar y separar el articulado relativo a la modificación y la extinción de las obligaciones que el Código reglamenta conjuntamente en los artículos 1.156 y ss. También es necesario considerar detenidamente si pueden modificarse todos los elementos de la obligación o sólo aquellos no determinantes de la identidad de la misma. Asimismo, se debe producir el deslinde entre las figuras de la novación y de la modificación. El régimen de la cesión de créditos debe analizar el problema del empeoramiento de condiciones del deudor inconsentido. Igualmente es necesario separar y aclarar convenientemente las figuras de la delegación, expromisión y asunción de deudas. Del mismo modo, toda la regulación debe tener en consideración la problemática que introducen las condiciones generales de contratación. En fin, deben corregirse los diversos errores de dicción del Código (v. gr. el artículo 1.212 al referirse a los "poseedores de hipotecas" en realidad alude a los propietarios de las fincas gravadas).

Por otra parte, en el siglo XX hemos asistido a lo que se ha denominado la masificación y la estandarización de la materia contractual a través de la figura de las condiciones generales de la contratación y la búsqueda de remedios frente a los abusos que dicha figura puede generar. El ocaso de dicho siglo y el principio del presente han consolidado el fenómeno conocido como globalización y la consiguiente multiplicación de los mercados y de las relaciones de tráfico externo. Finalmente, desde diversas estructuras políticas supranacionales se ha impulsado la codificación de cuerpos de derecho que se ocupan de esta materia para hacer frente a las nuevas necesidades. De todos estos esfuerzos cabe destacar la Convención de las Naciones Unidas sobre la Venta Internacional de Mercaderías, elaborada por la Comisión de las Naciones Unidas para la Unificación del Derecho Mercantil (UNICTRAL) y adoptada en Viena en 1980, los llamados Principios sobre los Contratos Comerciales Internacionales elaborados por el Instituto Internacional para la Unificación del Derecho privado europeo (UNIDROIT), los Principios de Derecho europeo de contratos y, en fin, las diversas Directivas comunitarias que van conformando un Derecho europeo de contratos.

Por ello, resulta necesario acometer una profunda reforma de los preceptos del Derecho general de obligaciones y contratos contenidos en los Títulos I y II del Libro IV del Código civil (arts. 1.088 al 1.314) que los ponga en consonancia con las últimas iniciativas citadas. No se trata de un mero pro- 
blema estético, sino que existen importantes problemas de coherencia interna del conjunto normativo, amén de la necesidad de dar respuesta a las cuestiones jurisprudenciales y dogmáticas aún no resueltas, con especial consideración de la europeización del Derecho de contratos. Así lo ha hecho Alemania con la llamada Ley de Modernización del Derecho de Obligaciones del año 2001. También debemos aludir a los procesos de reforma iniciados en Francia y en otros países europeos. En consecuencia debe acogerse muy positivamente la reciente propuesta para la modernización del Derecho de obligaciones y contratos que ha elaborado la Comisión General de Codificación.

En definitiva, nuestro Código civil necesita desde hace mucho tiempo un rejuvenecimiento y no una mera operación de restyling. A lo largo de esta exposición hemos visto los problemas terminológicos, sistemáticos y prácticos que presenta el objeto de nuestro trabajo, aunque la problemática afecta a todo el Derecho general de obligaciones y contratos. Ciertamente, es difícil encontrar el momento, sobre todo político, para iniciar una recodificación. En los tiempos que vivimos hay que armarse de valor para una recodificación total o parcial. Pero es imperioso poner en consonancia nuestro viejo Derecho de obligaciones con el marco comparado, el Derecho comunitario y el Derecho internacional. Finalmente, la convicción de que las leyes son mucho mejores cuanto más claras y accesibles debe retronar en una cultura jurídica, como la nuestra, en la que la mala calidad de las leyes parece ser ya un lugar común irremediable. 